\title{
Laboratory apparatus and techniques for the rearing and insecticidal treatment of whitefly Bemisia tabaci (Homoptera: Aleyrodidae) under simulated field conditions
}

\author{
Mark Rowland, Barry Pye, Mary Stribley, Barbara Hackett, \\ Ian Denholm, and Roman M. Sawicki \\ AFRC Institute of Arable Crops Research, Rothamsted \\ Experimental Station, Harpenden, Herts, UK.
}

\begin{abstract}
Laboratory apparatus and techniques are described for the rearing and insecticidal treatment of whitefly, Bemisia tabaci Gennadius, under simulated field conditions. Insects were reared on cotton plants inside large population cages and treated from an overhead sprayer. The effects of these treatments were assessed accurately, without interfering with insects or plants, by monitoring adult numbers with an endoscope over one or more generations. Examples of single-generation and multiple-generation tests with cypermethrin are described. The apparatus is suitable for testing strategies for delaying the selection of resistance (e.g. using insecticides applied singly, alternately, or in mixture, at various application rates and frequencies), for controlling populations already resistant to insecticides, and for integrated pest management using chemical and biological control agents together.
\end{abstract}

Introduction

The emphasis in laboratory studies of insecticide resistance has advanced from the purely toxicological and biochemical to the development of theoretical strategies, based upon computer simulations, for delaying the selection of resistance in the field (Curtis, 1981, 1985; Curtis et al., 1978; Denholm et al., 1987; Georghiou \& Taylor, 1977; Mani, 1985; Wood \& Mani, 1981).

The practicability of such strategies is limited by the ecological and behavioural assumptions built into the population genetics' models (Taylor, 1983) and by the artificiality of laboratory insecticide bioassays upon which the models are usually based (Denholm et al., 1987). This problem can be overcome by devising laboratory techniques and experiments which mimic the way the pest lives, reproduces and is exposed to insecticides in the field (Denholm et al., 1986).

Correspondence: Dr M. Rowland, AFRC Institute of Arable Crops Research, Rothamsted Experimental Station, Harpenden, Herts. AL5 2JQ, UK.
With this as our aim, we devised and tested apparatus and techniques for rearing, monitoring and-treating populations of insecticide-susceptible and resistant Bemisia tabaci on cotton plants in a self-contained laboratory system that simulates field conditions.

We describe here this apparatus and demonstrate its potential for evaluating insecticide treatments over single and multiple generations of whitefly.

\section{Apparatus and techniques}

B. tabaci populations are reared continuously on cotton plants in cotton-field simulators and sprayed with insecticide at intervals using a self-propelled sprayer. The efficacy of the treatments is assessed by monitoring changes in adult numbers. All operations are done in situ without interference to plants or insects.

\section{Simulator}

Each simulator consists of three contiguous sections (fig. 1): a sprayer in its housing unit at the front; a cage 


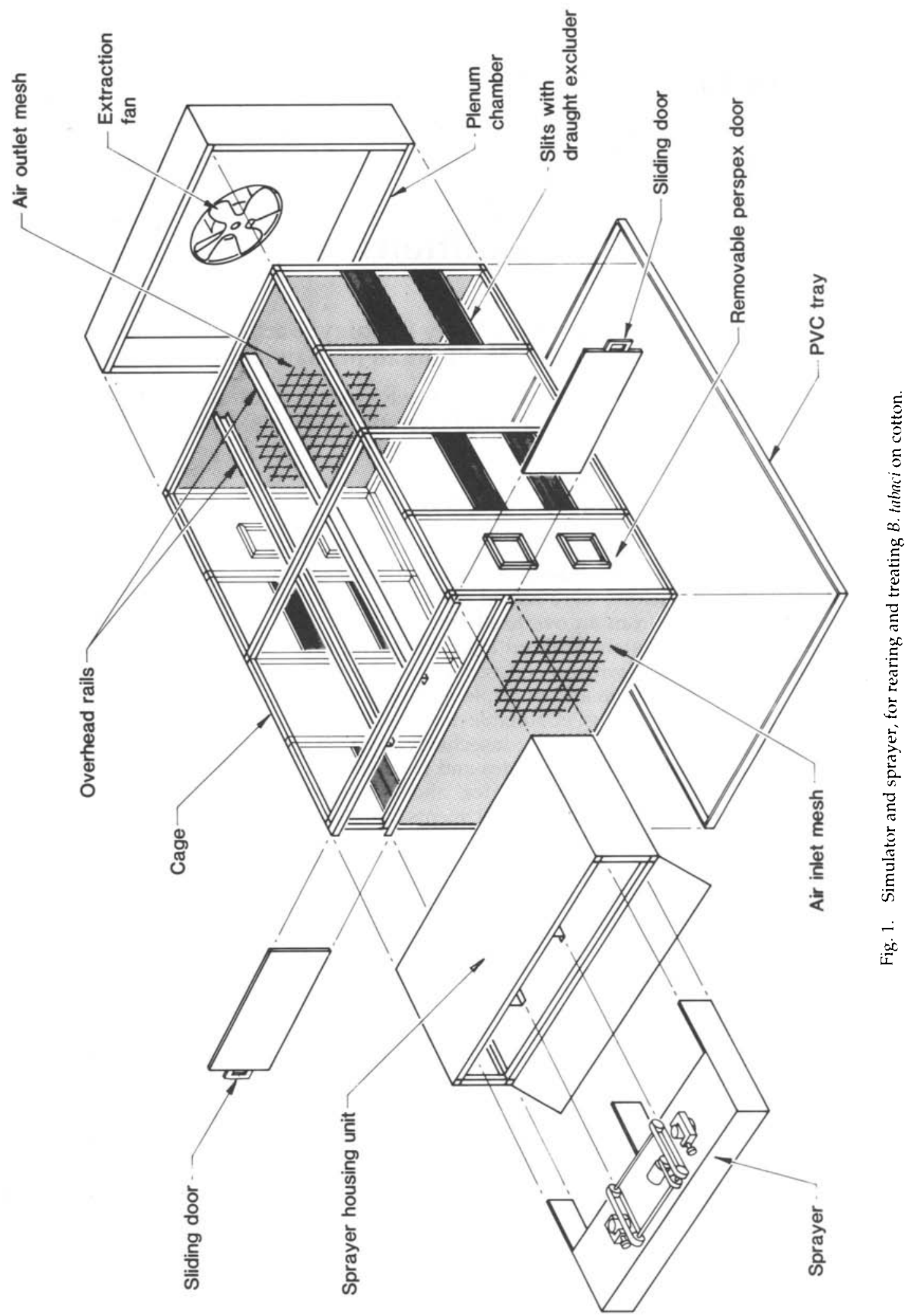


holding the plants and insects in the middle; and a plenum chamber with an exhaust fan at the rear.

The sprayer housing unit, an aluminium box $(60 \mathrm{~cm}$ long, $100 \mathrm{~cm}$ wide, $25 \mathrm{~cm}$ high) with a door at the front and open-ended at the back, abuts against a pair of sliding doors which provide access into the cage. The sprayer hangs from the roof of the housing unit, on rails which line up with rails running the length of the cage Ports on each side of the housing unit provide access to a drip tray which is attached to the sprayer when the sprayer is moved between simulators.

The cage (170 cm long, $120 \mathrm{~cm}$ wide, $100 \mathrm{~cm}$ high) is made of 'handy-tube ${ }^{R}$ square steel tubing (manufactured by Link 51 Ltd, P.O. Box 16, Mill St, Brierly Hill, W. Midlands, DY5 2TB) and rests on a floor tray made of heavy-duty PVC. The top and six of the eight side panels are glazed; the remaining two side panels are fitted with removal perspex doors with pairs of openings covered with fabric sleeves for access into the cage. Additional access is through nylon-brush draught excluders inserted at two heights in alternate side panels. The draught excluders provide self-sealing apertures through which the endoscope, water-hose lance and other instruments can be inserted into the cage without releasing insects. Vermiculite on the floor of the cage absorbs the insecticide not intercepted by plants. The ends of the cage are made from fine steel mesh to provide ventilation. Above the cage are banks of fluorescent and tungsten lights.

The plywood plenum chamber $(20 \mathrm{~cm}$ long, $140 \mathrm{~cm}$ wide, $100 \mathrm{~cm}$ high) contains a $32 \mathrm{~cm}$ diameter variablespeed fan to draw air uniformly through the cage, simulating a light breeze $(0.2 \mathrm{~m} / \mathrm{s})$.

\section{Sprayer}

The sprayer, custom-made from heavy-duty PVC, and powered by a $12 \mathrm{~V}$ battery, has 3 main mechanical components: a motor drive, spinning-disc controlled droplet applicators (CDAs), and a peristaltic pump (fig. 1).

The drive unit (a $12 \mathrm{~V}$ variable speed motor driving caterpillar tracks) propels the sprayer along overhead rails forward into the cage and back into its housing unit. Speed is adjustable but in most experiments was kept at $11 \mathrm{~cm} / \mathrm{sec}$ to simulate the volume per hectare applied to cotton in the Sudan (Uk \& Courshee, 1982).

The $1.1 \mathrm{~m}$ wide spray swath is generated by a pair of Mantis $^{R}$, CDAs (manufactured by Mantis $\mathrm{GmbH}$, D-2000 Hamburg, 74, Am Schiffbiker Berg 14, West Germany) arranged symmetrically within the body of the sprayer (for droplet sizes between 50 and $250 \mu \mathrm{m}$ volume median diameter), or by a single, larger, centrally-placed CDA for larger droplet sizes (fig. 1).

The peristaltic pump (101 FD/R variable-speed pump, manufactured by Watman-Marlow, Falmouth, Cornwall, TR11 4RU) transfers the insecticide solution from the reservoir to the CDAs.

Switches for the electrical relays controlling the three mechanical components are positioned on a panel on the rear of the sprayer. All spray parameters can be varied: the volume of insecticide released is controlled by the speed of the machine and by the flow rate of the pump; droplot size is controlled by the angular velocity of the CDAs. We used throughout two CDAs adjusted to deliver a droplet size ca. $70 \mu \mathrm{m}$ diameter at a low rate of 30 litres/hectare, similar to that sprayed from the air in the Sudan (Uk \& Courshee, 1982).

To produce an even distribution of insecticide across the width of the cage, only the leading arc (24\% of the total spray delivered), subtended between a central and two outer baffles, leaves the sprayer. The remaining $76 \%$ of spray collects inside the sprayer and is channelled away. The outer baffles prevent contamination of the sides of the cage.

Because the forward velocity of the sprayer is greater than the settling speed of the spray, the CDAs are set to operate only on the return journey. At the start of the operation the sprayer travels along the overhead rails to the rear of the cage with the CDAs switched off. On reaching the far end, a protruding switch on the central baffle strikes the cage, reverses the drive, and switches on the peristaltic pump and CDA relays. A time delay module in the drive relay ensures that the sprayer starts its return journey only when the CDAs reach full angular velocity and this ensures uniform spraying during the return journey. A trip switch on the rear panel of the sprayer switches off all the relays on striking the door of the housing unit. The plenum chamber fan is switched off during spraying to allow even deposition within the cage and minimal contamination of the sides.

\section{Establishing and monitoring whitefly infestations}

The simulators are kept in a 16:8 h light:dark regime in a controlled temperature room set at $26 \pm 2{ }^{\circ} \mathrm{C}$. The heat generated by the overhead lights does not create hot spots or marked temperature gradients within the cages.

The cotton plants (variety: deltapine 16) are grown in small pots $(8 \mathrm{~cm}$ diameter, $6 \mathrm{~cm}$ high) to reduce rate of growth, and are fed with sticks of commercial multifertilizer formulation. The plants are placed in the cages when two to four nodes high, and can be kept for ten weeks $(75 \mathrm{~cm}, 16$ nodes high). During this period the plants provide food and shelter for three generations of tabaci.

The cotton plants are uniformly infested by sprinkling adult tabaci (lightly-anaesthetized with $\mathrm{CO}_{2}$ or by chilling) onto 8-11 closely grouped plants which are then set out in two rows of four (sometimes with a central row of three), to form the treatment plots for the following ten weeks.

Only adults are counted, in situ, using rigid endoscopes (manufactured by 'Stortz' and 'KeyMed') long enough $(57$ and $80 \mathrm{~cm}$ ) to reach all the plants through the brush borders on the sides of the cage. The fields of view $\left(64^{\circ}\right.$ and $\left.50^{\circ}\right)$ and depths of focus $(0$ to $\infty)$ are sufficient for entire leaves to be examined at close range. All adults can be counted accurately from outside the cage since they are not disturbed by the cold light from the fibre optic light source.

\section{Calibration of the sprayer and evaluation of spray patterns}

The sprayer was calibrated and spray distribution determined by measuring the amount of fluorescent material ( $3.0 \%$ aqueous solution of 'uvitex ${ }^{R}$, manufactured by Ciba Geigy, Simonsway, Machester, M22 5LB) intercepted by filter paper discs $(1.8 \mathrm{~cm}$ diameter $)$ placed 


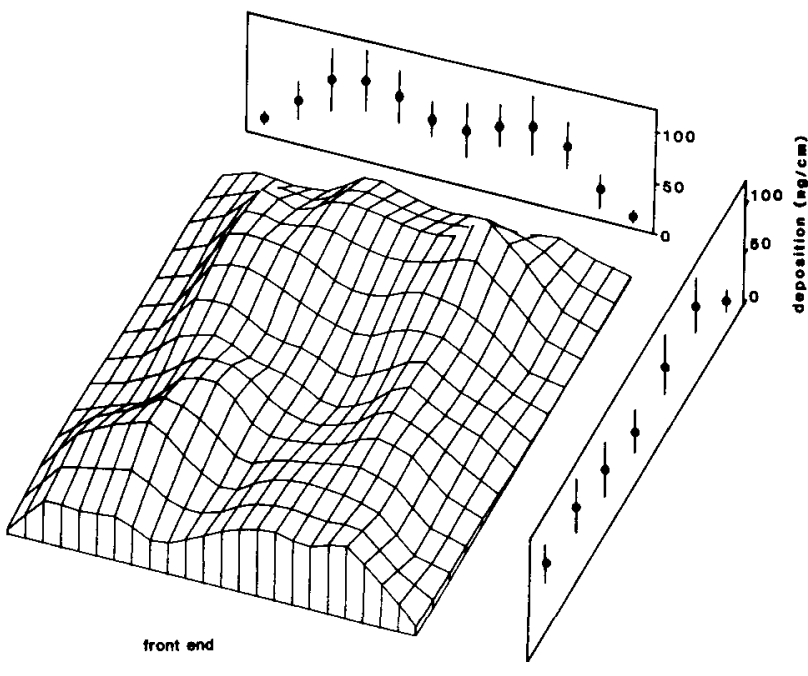

Fig. 2. Perspective block diagram of horizontal distribution of spray within the simulator.

within the cage or on plants. The 'uvitex ${ }^{R}$ ' was extracted from the discs with carbon tetrachloride, and quantified using a fluorimeter.

\section{Horizontal deposition}

This was investigated by spraying with 'uvitex $\mathrm{R}^{\mathrm{R}}$ seven rows of 12 discs on the floor of the cages. To illustrate the overall spray pattern, the results were transformed into a persepective block diagram (fig. 2).

The mean deposit for each of the seven rows, excluding the row nearest the plenum chamber, was very regular (fig. 2), and as expected there was very little spray deposited along the edges of the cage. Thus virtually all the spray fell uniformly within the floor area normally occupied by cotton.

The spray deposit was somewhat M-shaped in crosssection, with a slight dip where the two swaths met. This shape was an unavoidable consequence of having to use two sprayers to give the desired swath width and droplet size.

The consistency of deposition between spray runs was tested by measuring on six separate occasions the amount of 'uvitex ${ }^{R}$ ' intercepted by a row of discs positioned across the width of the cage floor. The mean deposition and $95 \%$ confidence interval varied little from one spray run to another $(F=0.8 ;$ d.f. $=5,44 ; \mathrm{P}>0.05)($ fig. $3 \mathrm{~A})$.

\section{Vertical deposition}

By attaching filter paper discs on wooden scaffolds at various heights in different parts of the cage, it was possible to measure the vertical deposition of the spray. Fig. $3 \mathrm{~B}$ shows that deposition was consistent at all heights $(\mathrm{F}=0.4 ; \mathrm{d} . \mathrm{f} .=4,20 ; \mathrm{P}>0.05)$.

\section{Deposition on cotton plants}

Distribution was determined on fourteen 14-leaf cotton plants positioned at regular intervals within the cage. Four filter paper discs were glued to upper and lower surfaces of alternate leaves: two discs next to the tip, and two next to the petiole. After spraying, the surface areas of all the leaves were measured with a planimeter and internode distances were measured with a ruler. The experiment was repeated twice.

With aerial spraying it is not possible to acheive uniformly high deposits of insecticide on all leaves. Interception of sedimenting droplets by canopy leaves produces a vertical profile of deposition which takes the form of an exponential decay curve, as described by the following equation (Bache \& Uk, 1975; Uk \& Courshee, 1982)

$$
D_{h}=D_{0} \exp (-\beta h)
$$

where $D_{\|}$is the deposit density at the top of the canopy, $D_{h}$ is the deposit density at $h \mathrm{~cm}$ from the top, and $\beta$ is the attenuation coefficient. The value of $\beta$ can be estimated from the slope of the regression of $\ln D_{\mid l} / D_{k}$ against $h$ for the different leaf heights (Bache \& Uk, 1975 ), and in the present experiment was found to have a value of $0.078 / \mathrm{cm}$.

The value of $\beta$ for a crop is mainly determined by the leaf area index (LAI = total area of one side of the leaves of a plant divided by the corresponding ground area). In fig. 4, the mean deposit on leaves at each node was compared with an expected value, the calculation of which assumes that the proportion of spray intercepted by leaves is equal to the leaf area index for that node:

If the ground area covered by the plants $=X \mathrm{~cm}^{2}$, and the total area of the topmost leaf $=Y_{1} \mathrm{~cm}^{2}$, then the proportion of total spray intercepted by the topmost leaf $=Y_{1} / X$.

If the mean spray deposit on topmost

leaf $=Z_{1} \mathrm{ng} / \mathrm{cm}^{2}$,

then the expected mean deposit on the leaf below, $Z_{2}=Z_{1}\left(1-Y_{1} / X\right)$.

When the leaf area at this node is $Y_{2}$, the expected mean deposit on the leaf below, $Z_{3}=Z_{2}\left(1-Y_{2} / X\right)$, etc.

In theory the expected values decrease as each leaf node intercepts a proportion of the spray equal to that leaf node's LAI. In practice the observed mean values of the upper leaf nodes (nodes 8-12) were greater than expected, and those for the lower nodes (nodes 2-6) were smaller than expected (fig. 4A-D). This was because the upper canopy arranges itself to intercept maximum light, shielding the lower leaves. The total LAI for the 14-node plants was 2.4

Relatively little spray was desposited on the undersurfaces of leaves (fig. 4A-B): the ratio between under surface and upper surface deposits was 1:160 for canopy leaves and 1:5 for lower leaves. Undersurface deposition near the petioles was similar for all nodes whereas deposition near the leaf tips was greater in the canopy than for lower leaves (paired sample t-test, $P<0.05$ ) possibly due to convection currents or air turbulence.

\section{Toxicological bioassays}

Because the simulator bridges laboratory and field studies, it has the potential to resolve many shortcomings of conventional toxicological bioassays. The following examples illustrate two approaches for evalu- 
A

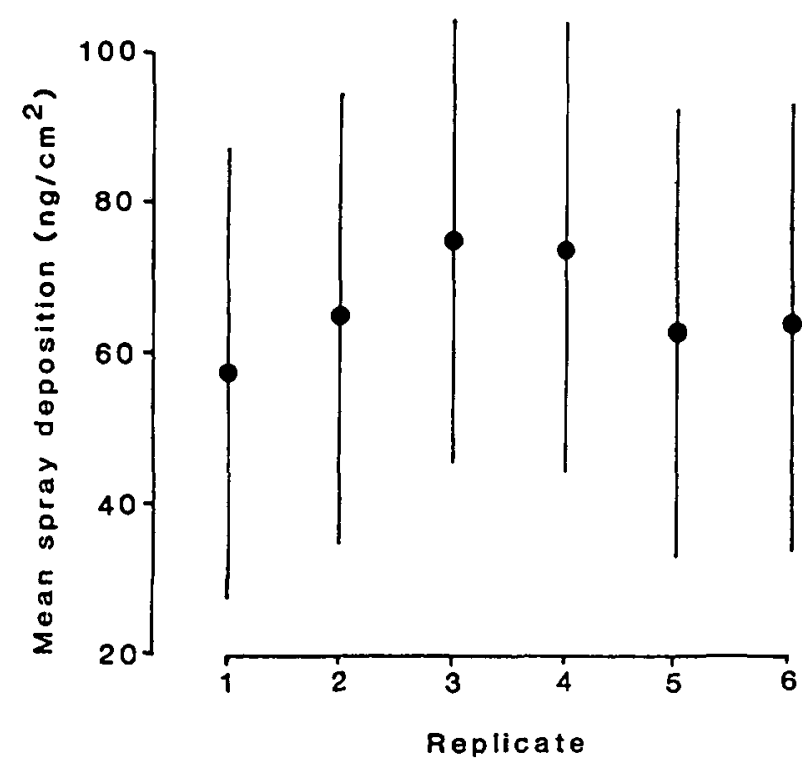

B

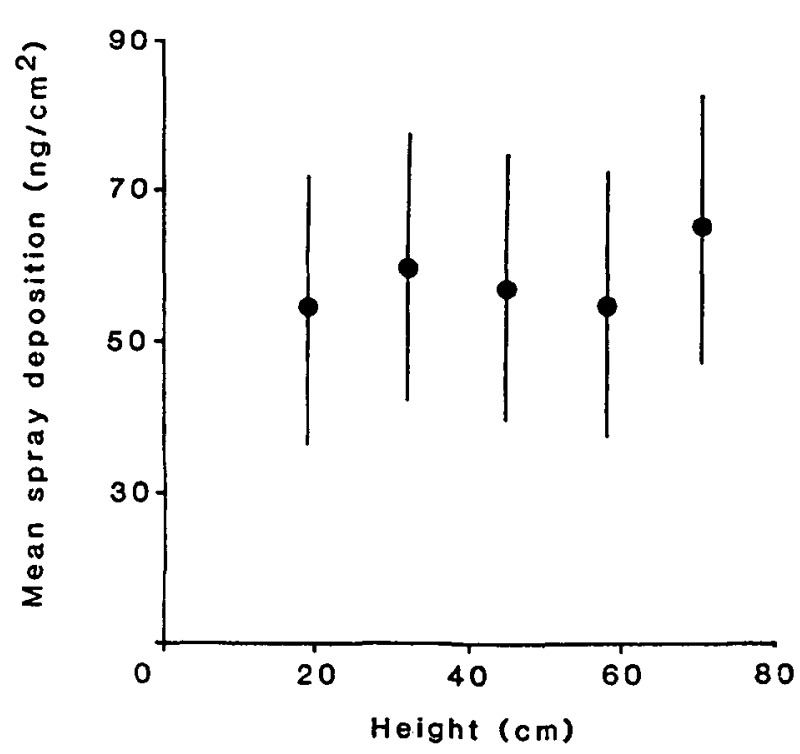

Fig. 3. A. Repeatability of spray deposition across the floor of the simulator (mean $\pm 95 \% \mathrm{CI}$ ). B. Deposition of spray (mean $\pm 95 \%$ CI) at various heights within the simulator.

ating more realistically the impact of pesticide treatments on pest numbers.

\section{Single generation experiments}

Each simulator was seeded with approximately 500 of an insecticide-susceptible adult tabaci; $24 \mathrm{~h}$ later the number of adults settled on the leaves were counted using the endoscope. The four simulators were then sprayed with different dosage rates of cypermethrin and adult numbers monitored at one to two day intervals for seven days.

There was a positive correlation between dosage rate and reduction in infestation up to $50 \mathrm{~g}$ cypermethrin/ha, the recommended field rate, but greater dosage rates did not increase kill (fig. 5). Thus, short-term experiments in the simulators can be useful for determining optimal field dosage rates.

It is important to note that simulator bioassays do not necessarily measure mortality per se; they merely measure the number of adults remaining on plants after treatment. Insects no longer present on plants may have been irritated or repelled, rather than killed, and may resettle later. However, provided the reduction in infestation is permanent, as in the example described above, it is appropriate and less confusing to use the term mortality when comparing the proportions 'lost' after different treatments.

\section{Multiple generation bioassays}

To find out whether an insecticide will give adequate control of tabaci, it is necessary to monitor adults for at least $\mathbf{1 8}$ days after treatment since larval mortality cannot be recorded directly ( 18 days is equivalent to one complete generation of tabaci). If the new adult generation emerging after treatment attains a size greater than the pre-treatment generation, either the insecticide was inadequate or the interval between treatments was too long. To obtain meaningful results, all life stages must be present at the time of treatment, a situation most easily achieved by withholding treatment until at least 18 days after the initial inoculation of adult females. Thereafter cages are sprayed at pre-decided intervals or whenever specified adult thresholds are breached.

In the example shown (fig. 6) we examined the long term response of tabaci to cypermethrin, and compared it with a computer simulation of population growth in the absence of insecticides, using data on mortality and fecundity derived from life table experiments (M. Rowland, in prep.). Plants were infested with 60 females and sprayed with $50 \mathrm{~g}$ cypermethrin/ ha (the optimal dosage-see fig. 5) whenever the adult population grew to more than 20 per leaf (i.e. on days 21 and 40 ).

The first treatment with cypermethrin quickly reduced adult numbers to below the threshold (fig. 6). However, this non-translaminar insecticide was unable to kill the large numbers of eggs and larvae present on the leaf undersurfaces, and many third generation adults began to emerge around day 36. A further cypermethrin treatment killed some of these adults but by this stage the plants were deteriorating rapidly. We can conclude from this test that treatment with cypermethrin once per generation is insufficient to control resistant tabaci. 


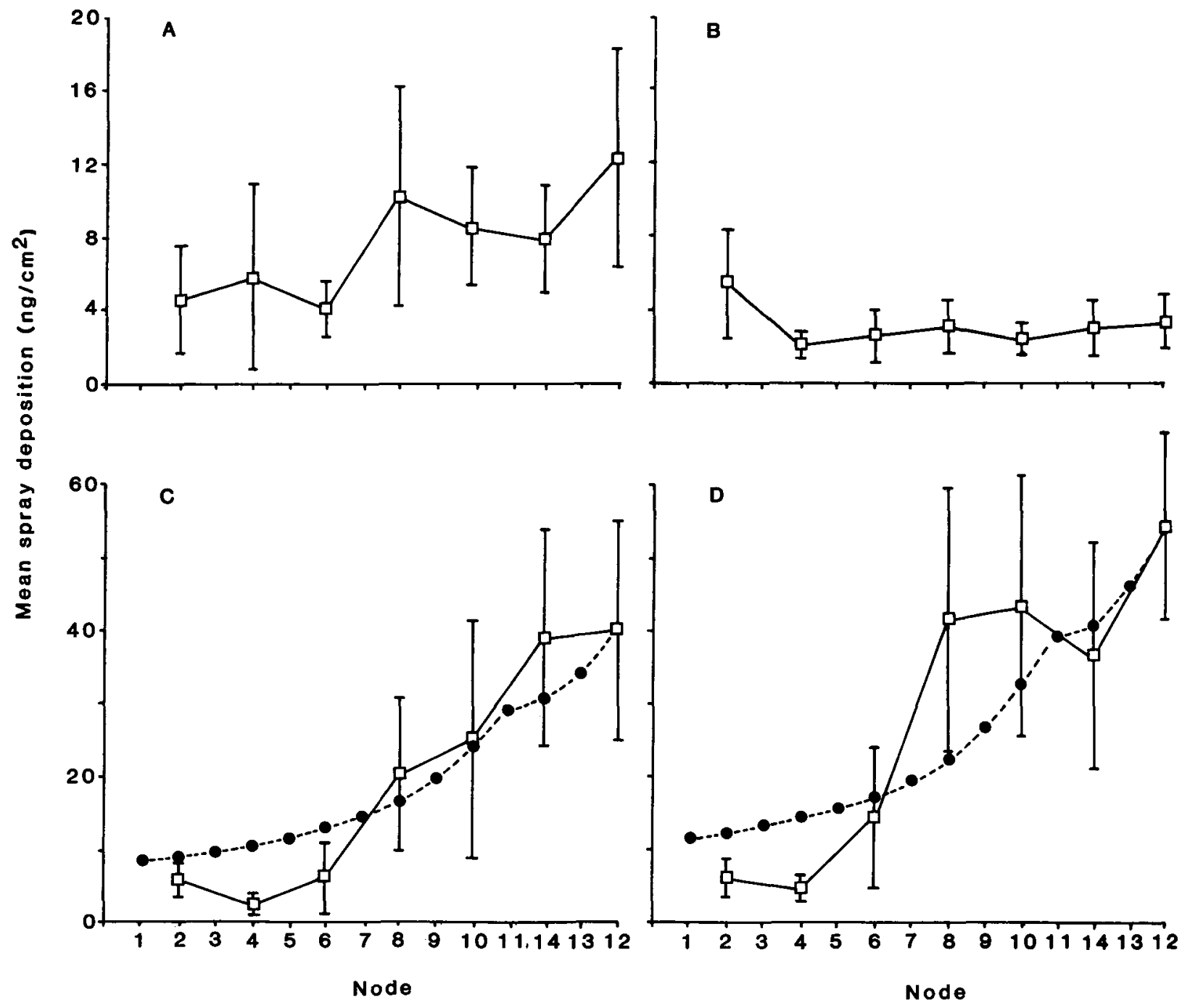

Fig. 4. Deposition of spray (mean $\pm 95 \% \mathrm{CI}$ ) on 14-leaved cotton plants within the simulator: A. leaf undersurface near apex, B. leaf undersurface near petiole, C. leaf undersurface near apex, D. leaf undersurface near petiole. ( $\square-$ observed values, $-\bullet-$ expected values based upon leaf area index).

\section{Discussion}

The main considerations when designing the simulator were:

1. Conditions within the cage should approximate those in the field.

2. Insecticide treatments should be realistic but cause minimal contamination of the cage.

3. Monitoring of tabaci after treatment should cause minimal disturbance to insects or plants.

4. The techniques should be versatile so that various field control problems can be addressed.

These considerations were largely met: the environment within the cage seems to favour normal develop- ment of plants and insects, disturbances can be kept to a minimum because none of the operations (counting, watering, spraying) interferes with insects or plants, and events in the cage can be closely monitored by frequent use of the endoscopes.

The performance of the sprayer was satisfactory. To obtain the desired swath width and droplet size, two CDAs were required, and this led to some variation in deposition across the width of the cage. However, this variation was consistent and even trivial when compared with the natural variation in deposition between leaves due to interception of spray by the upper canopy.

The vertical attenuation rate $\beta$ on $0.6 \mathrm{~m}$ high plants inside the simulator was $0.078 / \mathrm{cm}$, a slightly greater 


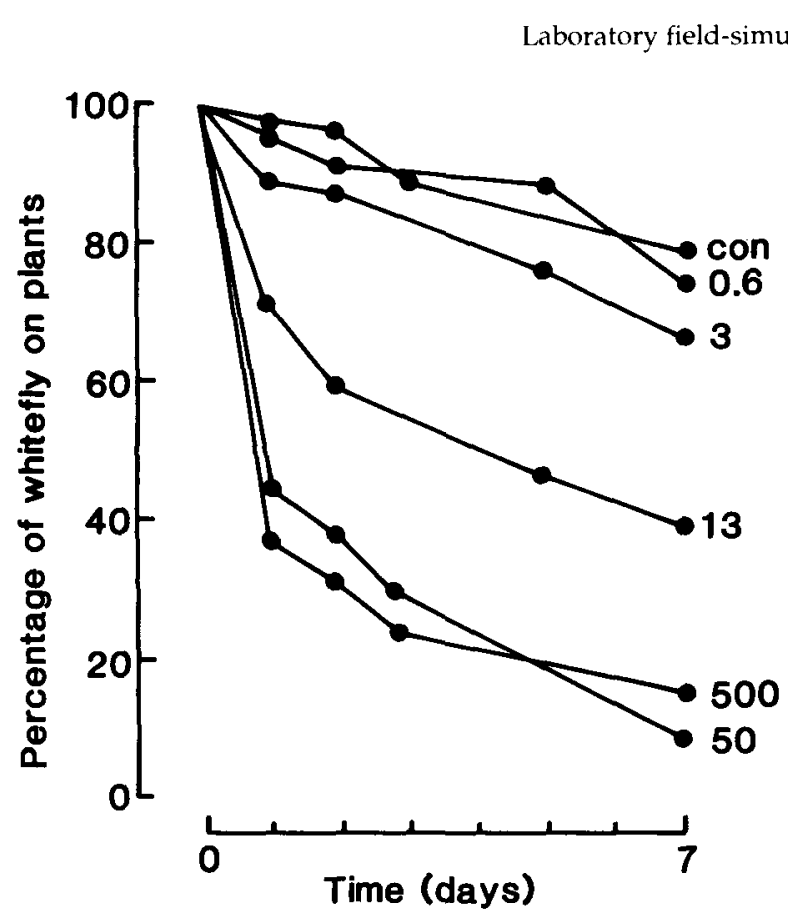

Fig. 5. Single generation test: percentage of adult $B$. tabaci remaining on plants after spraying with various dosages (in $\mathrm{g} / \mathrm{ha}$ ) of cypermethrin (see figure for details of dosages used).

value than the $0.042 / \mathrm{cm}$ and $0.018 / \mathrm{cm}$ obtained in the field by Bache \& Uk (1975) and Uk \& Courshee (1982) using 1-1.5 m plants. However, the results still compare favourably since tabaci in the simulator would meet a similar range of residue densities to that in the field: residue densities in the simulators decreased from $100 \%$ of application rate at the canopy top to $0.9 \%$ at tray level, and in the field from $100 \%$ at the top to $1.5-6.7 \%$ at ground level. Indeed, the higher $\beta$ in the simulator can be seen as fortuitous since plants are unable to reach full field size, growth being limited by the height of the cage. The lower values of $\beta$ for the field may be due to turbulence carrying droplets deeper into the canopy (Uk \& Courshee, 1982). Turbulence is also responsible for higher deposition on undersurfaces in the upper canopy than could be achieved in the simulator (Uk \& Courshee, 1982). In the simulator air movement had to be minimized during spraying to prevent contamination of the sides of the cage.

The simulation system is extremely versatile Treatment parameters such as droplet size, insecticide concentration and flow rate can be varied at will. Insecticides can be applied singly, alternately or in mixture, thereby allowing evaluation of potential whitefly management strategies. In addition, the simulator and the methodology can be adapted to study other pest species or even integrated control using chemical and biological control agents together.

\section{Acknowledgements}

This project is funded by a grant from Ciba-Geigy, Basle, and we thank Dr V. Dittrich, Dr G. Voss and col-

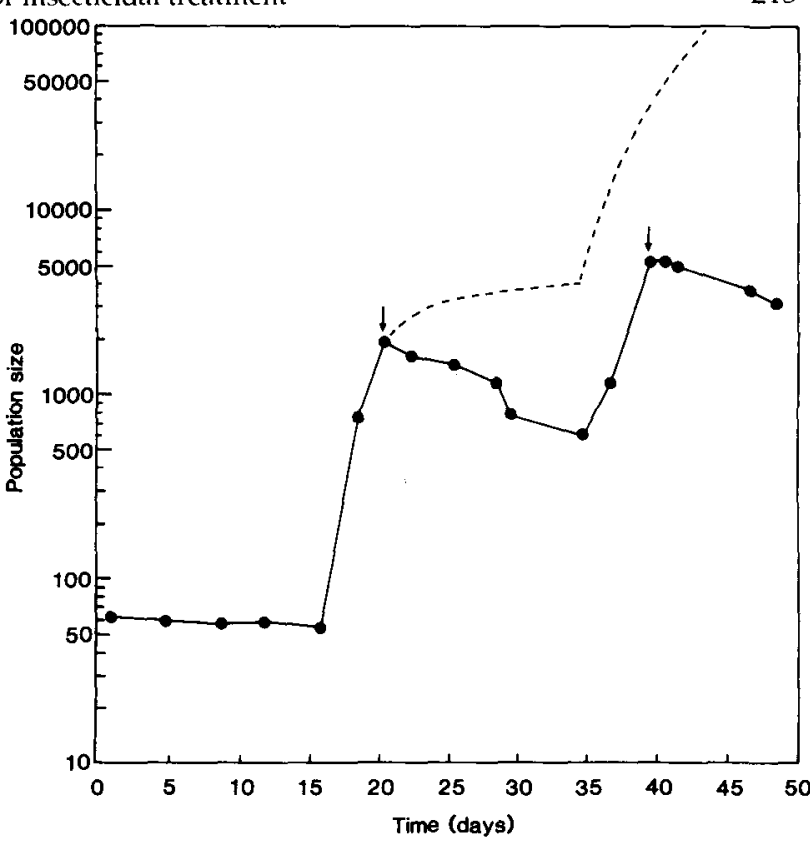

Fig. 6. Multiple generation test: changes in adult population size over three generations. The population was treated with $50 \mathrm{~g}$ cypermethrin/ha) on the 21 st and 40 th days (see arrows) The dashed line shows theoretical, unlimited population growth in the absence of cypermethrin treatment.

leagues for their help, advice and interest. We also thank Mr B. Edwards, Mr A. Hobbs and colleages for constructing the simulators, A. Hobbs for drawing fig. 1, and Dr C. Kershaw for statistical advice.

\section{References}

Bache, D.H. \& Uk, S. (1975) Transport of aerial spray, II. transport within a crop canopy. Agricultural Meteorology 15, 371-377.

Curtis, C.F. (1981) Possible methods of inhibiting or reversing the evolution of insecticide resistance in mosquitoes. Pesticide Science 2, 557-564.

Curtis, C.F. (1985) Theoretical models of the use of insecticide mixtures for the management of resistance. Bulletin of Entomological Research 75, 259-265.

Curtis, C.F., Cook, L.M. \& Wood, R.J. (1978) Selection for and against insecticide resistance and possible methods for inhibiting the evolution of resistance in mosquitoes. Ecological Entomology 3, 273-287.

Denholm, I., Sawicki, R.M., Farnham, A.W. \& White, J.C. (1986) Evaluation of a method for maintaining agestructured housefly populations to study the evolution of insecticide resistance. Bulletin of Entomological Research 76, 297-302.

Denholm, I., Sawicki, R.M. \& Farnham, A.W. (1987) Laboratory simulation of selection for resistance, pp. 138-149 in Ford, M.G., Hollomon, D.W., Khambay, B.P.S. \& Sawicki, R.M. (Eds) Biological and chemical approaches to combating resistance to xenobiotics. Chichester, Ellis Horwood.

Georghiou, G.P. \& Taylor, C.E. (1977) Operational influences in 
the evolution of insecticide resistance. Journal of Economic Entomology 70, 653-658

Mani, G. S. (1985) Evolution of resistance in the presence of two insecticides. Genetics 109, 761-783.

Taylor, C.E. (1983) Evolution of resistance to insecticides: the role of mathematical models and computer simulations, pp. 163-173 in Georghiou, G.P. \& Saito, T. (Eds) Pest resistance to pesticides. New York and London, Plenum Press.

Uk, S. \& Courshee R.J. (1982) Distribution and likely effective- ness of spray deposits within a cotton canopy from fine ultralow-volume spray applied by aircraft. Pesticide Science 13, 529-536

Wood, R.J. \& Mani, G.S. (1981) The effective dominance of resistance genes in relation to the evolution of resistance. Pesticide Science 12, 573-581.

(C) C.A.B International, 1990 